\title{
Prospective life cycle assessment of bio-based adipic acid production from forest residues
}

\author{
Rio Aryapratama ${ }^{\mathrm{a}, \mathrm{b}}$, Matty Janssen ${ }^{\mathrm{a}, *}$ \\ ${ }^{a}$ Environmental Systems Analysis, Department of Energy and Environment, Chalmers University of Technology, SE-412 96 Göteborg, \\ Sweden \\ ${ }^{b}$ Institute of System Sciences, Innovation and Sustainability Research, University of Graz, A-8010 Graz, Austria
}

\begin{abstract}
Environmental concerns related to the production of bulk chemicals are growing. Researchers and technology developers are currently looking into alternative production pathways for such chemicals by utilizing renewable resources, such as lignocellulosic feedstocks. Adipic acid is an example of such a bulk chemical, and its conventional fossil-based production emits significant amounts of $\mathrm{N}_{2} \mathrm{O}$, a major greenhouse gas. In this study, a prospective life cycle assessment (LCA) of bio-based adipic acid production from forest residues at an early development stage, situated in Sweden, was conducted. Acid-catalyzed (using $\mathrm{SO}_{2}$ ) and alkaline (using $\mathrm{NaBH}_{4}$ ) pretreatment were employed and scenarios and sensitivity analyses were conducted. The potential environmental impacts of this technology under development were compared to those of conventional adipic acid production. The results show that bio-based adipic acid production has a lower impact on global warming, eutrophication and photochemical ozone creation compared to fossil-based production. In contrast, it has a higher impact on acidification. An increased efficiency of mitigating $\mathrm{N}_{2} \mathrm{O}$ emissions from the fossil-based production may alter this comparison. Producing bio-based adipic acid using the alkaline pretreatment has a higher environmental impact than producing it using acid-catalyzed pretreatment. Furthermore, if biomass is used to fulfil process energy demands, instead of fossil fuel, the environmental impact of the bio-based production decreases. It is therefore important to reduce the amount of $\mathrm{NaBH}_{4}$ used in the alkaline pretreatment or to lower the environmental impact of its production.
\end{abstract}

Keywords:

life cycle assessment, prospective, adipic acid, forest residues, acid-catalyzed pretreatment, alkaline pretreatment

\footnotetext{
${ }^{*}$ Corresponding author

Email address: mathias. jans sen@ chalmers. se (Matty Janssen)
} 


\section{Introduction}

The increase of population, the growing concerns about climate change and issues related to non-renewable resource depletion encourage society to find alternative ways to divest from the fossil-based economy. The current fossil-based economy includes a wide range of chemical products, from large-scale bulk to high-value added fine chemicals. Environmental concerns related to the production of these chemicals are growing and potential solutions such as by increasing selectivity, reducing by-product formation, and developing multi-functional catalysts in order to minimize the number of reaction steps, are explored (Hoelderich, 2000). Another solution may be to substitute fossil-based, non-renewable resources and products with renewable ones, which leads to completely different production processes (Sandén and Pettersson, 2014).

Adipic acid $\left(\left(\mathrm{CH}_{2}\right)_{4}(\mathrm{COOH})_{2}\right)$ is considered as an important bulk chemical and is a pre-cursor for the production of nylon-6,6. About $80 \%$ of the world-wide adipic acid production is used for the production of this polymer (Shimizu et al., 2000), and its production increased almost 9-fold from 2000 to 2010 (Li et al., 2014). There are several industrial-scale production routes to produce adipic acid, and all of them are fossil-based. The most common route is via nitric acid oxidation of cyclohexanol and cyclohexanone, so-called ketone-alcohol (KA) oil (Shimizu et al., 2000). This production route also leads to the formation of nitrous oxide $\left(\mathrm{N}_{2} \mathrm{O}\right)$, one of the major greenhouse gases (GHG). Its climate impact is 298 times higher than that of carbon dioxide $\left(\mathrm{CO}_{2}\right)$ (Myhre et al., 2013). $\mathrm{N}_{2} \mathrm{O}$ emissions account for about $9 \%$ of global annual greenhouse gas (GHG) emissions, and currently, adipic acid production itself contributes almost $80 \%$ of total industrial $\mathrm{N}_{2} \mathrm{O}$ emissions (Li et al., 2014).

Despite the availability and implementation of $\mathrm{N}_{2} \mathrm{O}$ emission abatement technologies, $\mathrm{N}_{2} \mathrm{O}$ emissions remain as a major concern in climate change mitigation. The $\mathrm{N}_{2} \mathrm{O}$ emissions due to adipic acid production have been a motivation for finding an alternative production process in order to avoid $\mathrm{N}_{2} \mathrm{O}$ emissions. For instance, Wang et al. (2013) used a direct synthesis of adipic acid from cyclohexene using $\mathrm{H}_{2} \mathrm{O}_{2}$ as an oxidant (instead of nitric acid) in a continuous process, and conducted a life cycle assessment (LCA) to determine its environmental impact. Even though the results indicate lower impact on the climate, the authors emphasized that this route has disadvantages in several other life cycle impact categories, which indicate a potential environmental burden shifting. In a more recent study, Han (2016) performed experimental studies on adipic acid production through catalytic conversion of corn stover whose purpose it also was to lower $\mathrm{N}_{2} \mathrm{O}$ emissions. However, the study did not quantify the environmental benefits of this production route.

Another way to produce adipic acid is through biological conversion (Draths and Frost, 1994; van Duuren et al., 2011). Draths and Frost (1994) developed the microbial conversion of D-glucose into cis,cis-muconic 
acid followed by the reduction to adipic acid. van Duuren et al. (2011) performed process simulation and limited LCA studies of adipic acid production via the biological conversion of aromatic feedstocks (benzoic acid, impure aromatics, toluene, and phenol) from lignin to cis,cis-muconic acid. Both studies were conducted at a very early stage in the development of the process. Producing adipic acid via bioprocess pathways looks promising because, not only does it not emit $\mathrm{N}_{2} \mathrm{O}$, it also increases the use of renewable resources (biomass), instead of fossil-based raw materials (KA-oil). Forest residues, which mainly consists of branches and tops from commercial thinning, can be considered as such a promising renewable resource. In Sweden, approx. $8 \mathrm{TW}$ h of bioenergy is already generated from forest residues (Ortiz et al., 2014). Nevertheless, $80 \%$ of these residues are still left on the forest floor after harvesting, which suggests their availability as a feedstock (Ortiz et al., 2014). A previous study mentioned that using forest residues as a feedstock for adipic acid production can be considered as a promising alternative pathway (Svensson et al., 2015).

Considering that adipic acid bio-conversion technology is still at an early development stage, its environmental performance needs to be evaluated with assessment tools such as LCA, using a prospective perspective, in order to guide its further development. To the best of the authors' knowledge, there is only one study that conducted a limited LCA of bio-adipic acid production (van Duuren et al., 2011), which implies that a more comprehensive prospective LCA study is needed. Therefore, the purpose of the LCA study reported in this paper is to assess the potential environmental impacts and to identify the environmental hotspots of bio-based adipic acid production from forest residues in Sweden at an early development stage, and to compare it with the existing fossil-based production process. The LCA results are intended to guide the decision makers for further development towards a more environmentally benign adipic acid production technology and process.

\section{Materials and methods}

\subsection{System description}

The technical system under study is depicted in Fig. 1.

\subsubsection{Forestry activities}

In the upstream activities, firstly the forest residues from Norway Spruce harvesting are collected by a forwarder at the harvesting site and brought to the roadside. The forestry activities were assumed to take place approx. $50 \mathrm{~km}$ from the adipic acid plant, situated in Örnsköldsvik, Sweden. It was assumed that the timber extraction produced two different products: roundwood, which is the main part of the trees and the forest residues. Economic allocation is used to attribute environmental impacts from forest residue extraction. 


\subsubsection{Pretreatment}

The pretreatment fractionates the forest residues into cellulose, hemicellulose, free sugars, lignin, and other materials. There are two types of pretreatment used in this study: the acid-catalyzed and alkaline pretreatments. Sulfur dioxide $\left(\mathrm{SO}_{2}\right)$ is used for the acid-catalyzed pretreatment process. The pretreatment was conducted by adding steam at $212{ }^{\circ} \mathrm{C}$ and at 20 bar. The steam is generated by burning lignin and methane produced as a byproduct from the fermentation and anaerobic digestion (Fig. 1), respectively.

The alkaline pretreatment is performed by using a $7 \%(\mathrm{~m} / \mathrm{m})$ solution of sodium borohydride $\left(\mathrm{NaBH}_{4}\right)$ based on the mass of the forest residues. The process is then followed by mild steam explosion (STEX) at $110^{\circ} \mathrm{C}$. Next, the alkaline pretreatment by using sodium hydroxide $(\mathrm{NaOH})$ is performed.

\subsubsection{Neutralization and upstream separation process}

For both acid and alkaline pretreatment processes, the neutralization step is needed in order to adjust the pH to approx. 4.8, which is optimal for the hydrolysis and fermentation process. In case of acid-catalyzed pretreatment, $\mathrm{NaOH}$ was added, while hydrochloric acid $(\mathrm{HCl})$ was used to neutralize the pretreated material after the alkaline pretreatment. All materials then go into the upstream separation process (see Fig. 1) where the water with free sugars is discharged into the anaerobic digestion process which produces the biogas to fuel the steam generation. The rest of the materials are sent into the fermentation reactor.

\subsubsection{Hydrolysis and fermentation}

The flow into the hydrolysis and fermentation process is the pretreated forest residues which contains cellulose, hemicellulose, lignin, and other components (bark, ash, free sugars, etc.). The hydrolysis process produces fermentable sugars, undigested holocellulose, and unfermentable free sugars. The other components, including lignin, are only slightly affected by the hydrolysis process.

In the case of acid-catalyzed pretreatment, the Cellic Ctec 2 enzyme product is used to hydrolyze cellulose and hemicellulose. In the case of alkaline pretreatment, there is no enzyme used (Jedvert et al., 2012; Jedvert, 2014). The fermentation consists of the conversion of $C_{6}$ sugars to adipic acid via lysine (Burgard et al., 2013), and it was assumed that this two-step process can take place in one fermentation reactor to produce adipic acid. The required nutrient for the fermentation process was assumed to be ammonium sulfate $\left(\left(\mathrm{NH}_{4}\right)_{2} \mathrm{SO}_{4}\right.$.

\subsubsection{Downstream process}

The downstream process unit operations and their energy demands were based on a simulation study performed by Schweigler (2016). The evaporation of water and the concentration of adipic acid are the most energy intensive parts of the downstream process. Lignin is produced by the downstream process as by-product. 
The filtration unit produces relatively pure adipic acid while the other flows (water with dissolved chemicals and materials) are either recycled to increase the recovery of adipic acid, or are flowing to the anaerobic digestion (see Fig. 1). The steam needed in the downstream process is produced by burning fossil fuel and lignin. Meanwhile, the undigested part of hollocellulose and process water are sent to a wastewater treatment plant, which is considered outside of the system boundary.

\subsection{LCA description}

\subsubsection{Set-up of the $L C A$}

It was assumed that the adipic acid produced by the fossil-based and bio-based pathways has the same quality, and therefore can be compared using the same functional unit (FU). The FU in this study is set as $1 \mathrm{~kg}$ of adipic acid at the factory gate. The main goals of this study are a) to identify the environmental hotspots of bio-based adipic acid production from forest residues, and b) to compare the potential environmental performance of bio-based adipic acid with that produced via the conventional fossil-based pathway (Shimizu et al., 2000). This LCA study follows an attributional approach, from cradle to gate, since the purpose is to identify environmental hotspots to identify possibilities for improvement to guide the bio-based adipic acid technology development. The LCA model was built in openLCA 1.4 (Ciroth, 2007), an open source LCA software, in which the inventory modeling and life cycle impact assessment (LCIA) were performed. The LCIA was conducted using the CML (Institute of Environmental Sciences at Leiden University) characterization method (Guinée et al., 2002). The following environmental impact categories were used in the assessment:

\section{- Global Warming Potential (GWP)}

The production of bio-based instead of fossil-based adipic acid may lower the greenhouse gas (GHG) emissions, especially the $\mathrm{N}_{2} \mathrm{O}$ emissions. The GWP is a highly important impact category to show how significant the GHG emissions reduction of bio-based adipic acid production will be in comparison to that of the fossil-based process.

- Acidification Potential (AP)

This impact category is important to show the effect of bio-based adipic acid production on the acidity of soil and water. This impact category is mainly contributed by the emission of $\mathrm{SO}_{2}, \mathrm{NOx}$ and $\mathrm{NH}_{3}$ from the combustion of fossil fuel, biogas and lignin pellets.

- Eutrophication Potential (EP)

The phosphorous and nitrogen emissions from enzyme production, as well as emissions of nutrients from the fermentation process may lead to the increase of water and soil eutrophication.

- Photochemical Ozone Creation Potential (POCP). 
The combustion of fossil fuel, biogas, and combustion of lignin pellets will also emit NOx and volatile organic compounds, which could enhance the creation of photochemical ozone.

Furthermore, analyses on the consumption of both non-renewable (NREU) and renewable energy (REU) were performed by using the cumulative energy demand (CED) method (Frischknecht et al., 2007). The impacts due to direct and indirect land use change are omitted in this study, mainly because Swedish forest is well managed and there is no significant land use change taking place any more.

\subsubsection{Data collection, modeling and assumptions}

The life cycle inventory (LCI) data were collected from various sources, including experimental studies performed at Chalmers University of Technology, Sweden, scientific literature and reports, LCI databases (e.g. ecoinvent version 3.1 and US LCI), and process simulation studies.

The data for the emissions from and primary energy use during forestry harvesting were obtained from Liptow et al. (2013). Economic allocation was used to attribute the environmental impact of the forestry activities to the forest residues.

In the acid-catalyzed pretreatment process, sulfur dioxide $\left(\mathrm{SO}_{2}\right), 2.5 \%(\mathrm{~m} / \mathrm{m})$ based on dry forest residues weight, was added. The $\mathrm{SO}_{2}$ production was modeled in openLCA by using the ecoinvent process 'sulfur dioxide, liquid - RER' (Althaus et al., 2007). The alkaline pretreatment of lignocellulosic materials is mostly still in the early development stages or at laboratory experimental scale. To the best of the authors' knowledge, there is no LCA study yet on alkaline pretreatment of forest residues. In this study, the alkaline pretreatment data were acquired from experimental work performed by Jedvert et al. (2012) and Jedvert (2014). It was assumed that the experimental data can be applied at the industrial scale. The model for the $\mathrm{NaBH}_{4}$ synthesis route was built in openLCA and was based on the reaction of trimethyl borate and sodium hydride $(\mathrm{NaH})$ in the Brown-Schlessinger process (Wu et al., 2004). In the lab experiments, the mixture of $\mathrm{NaBH}_{4}$ and forest residues was left for up to $4 \mathrm{~d}$ to $5 \mathrm{~d}$ to achieve complete reactions. The production of $\mathrm{NaOH}$ was modeled by using the ecoinvent process 'sodium hydroxide, without water, in $50 \%$ solution state - RER' (Althaus et al., 2007), and the amount of $\mathrm{NaOH}$ added is $54.7 \mathrm{~g} \mathrm{~kg}^{-1}$ of dry matter. The production of $\mathrm{HCl}$, which is used in the neutralization step, was modeled by using the ecoinvent process 'hydrochloric acid, without water, in $30 \%$ solution state - RER'. The required amount of $\mathrm{NaOH}$ and $\mathrm{HCl}$ were estimated based on the study by Janssen et al. (2016). In the next stage, the upstream separation process, it was assumed that both outputs have an economic value of $70 € \mathrm{t}^{-1}$ (allocation point $\mathrm{B}$, see Fig. 1).

The data for enzyme usage for the fermentation were gathered from Karlsson et al. (2014) and were specific for forest residues in northern Sweden. It was assumed that these experimental data on enzyme dosage can 
also be applied at an industrial scale. The environmental impact data of enzyme production were taken from Liptow et al. (2013). It was assumed that the enzyme was produced in Kalundborg, Denmark, and delivered to the adipic acid plant via freight transport. The Danish fossil fuel mix (50\% oil, $29 \%$ coal and $21 \%$ natural gas) was used to model the fossil energy use of the enzyme production (Danish Energy Agency, 2011). In the fermentation process, the amount of $\left(\mathrm{NH}_{4}\right)_{2} \mathrm{SO}_{4}$ used as a nutrient was taken from van Duuren et al. (2011). Even though the pathway was different compared to this study, it was assumed that the required amount of $\left(\mathrm{NH}_{4}\right)_{2} \mathrm{SO}_{4}$ will not be significantly different. The production of $\left(\mathrm{NH}_{4}\right)_{2} \mathrm{SO}_{4}$ was modeled in openLCA by using the ecoinvent process 'ammonium sulfate, as $\mathrm{N}$ - RER'. The energy consumption due to mixing during the fermentation process was obtained from Palmqvist and Liden (2012).

The fossil-based energy used in the process was assumed to be the Swedish fossil fuel mix from 2011 (11\% coal, $82 \%$ oil and $7 \%$ natural gas), and was used for steam production (Energimyndigheten, 2014). Data related to the anaerobic digestion process (see Fig. 1) was taken from Janssen et al. (2016). The incineration of lignin for process energy needs was modeled using 'Combustion, dry wood residue - AP 42' process from the from US LCI database (NREL, 2012). It is assumed that the incineration of biogas generated by the anaerobic digestion, of the lignin and of the additional fossil fuel have efficiencies of $90 \%, 75 \%$ and $90 \%$, respectively. The partitioning of environmental burdens was done by means of economic allocation.

\subsubsection{Description of scenarios}

In the base case scenario (BC) (see Table 1), the lignin byproduct is burned to produce steam to fulfil part of the energy demand of the pretreatment, which cannot be entirely met by the biogas produced in anaerobic digestion only in the case of acid-catalyzed pretreatment. The other part of the steam produced by lignin combustion is used to provide energy to the downstream processing. However, to completely fulfil the energy demand in this scenario, extra steam needs to be produced. It is assumed that this is done by burning fossil fuel (Swedish fossil fuel mix).

In Scenario 1 ( $\mathrm{Sc1}$ ) (see Table 1), the steam production is free from fossil fuel use and the shortage of energy needed to produce all steam is supplied by burning wood chips. After being processed at the sawmill plant, the wood chips are sent to the incineration at the adipic acid plant site to be burned to produce energy. Economic allocation was used to partition environmental burden of wood chips at the sawmill plant. The burning of wood chips was modeled by using the 'Combustion, dry wood residue AP-42' process obtained from the US LCI database (NREL, 2012).

In Scenario 2 (Sc2) (see Table 1), the lignin by-product is sold as lignin pellets, and is not used to produce steam. This means that extra fuel would be needed to produce the steam. It is assumed, as in the base case 
scenario, that this extra fuel is fossil-based. The environmental impact of adipic acid production is partitioned over the adipic acid and lignin pellets using economic allocation, shown as 'allocation point $\mathrm{C}$ ' in Fig. 1. The adipic acid price (see Table 2) is assumed to be the median value of the price range stated in Boswell and Meehan (2011).

The lignin by-product is also sold as lignin pellets in Scenario 3 (Sc3) (see Table 1). However, the additional fuel for steam production is completely produced by burning wood chips as is the case in Scenario 1. As there is no lignin and fossil fuel incineration for steam production, this scenario has the highest amount of external biomass use.

These scenarios (see Table 1) were run for both the acid and the alkaline pretreatment cases. The fossilbased adipic acid production was used as the reference scenario, and compared with the scenarios of bio-based adipic acid production via both acid and alkaline pretreatment pathways. In openLCA, the fossil-based adipic acid production was modeled by using ecoinvent process 'adipic acid - RER' (Althaus et al., 2007).

\subsubsection{Sensitivity analyses}

Sensitivity analyses were conducted for the price of adipic acid and for the biomass burning efficiency, for both acid-catalyzed and alkaline pretreatments. For the adipic acid (AA) price sensitivity analysis, the lowest and highest prices were set at $1100 € \mathrm{t}_{\mathrm{AA}}^{-1}$ and $2500 € \mathrm{t}_{\mathrm{AA}}^{-1}$, respectively, according to Boswell and Meehan (2011) (see Table 2). For the biomass combustion efficiency, an increase from $75 \%$ to $90 \%$ was analyzed.

For the case of alkaline pretreatment, sensitivity analyses were conducted regarding the dosage of $\mathrm{NaBH}_{4}$ and the energy sources during $\mathrm{NaBH}_{4}$ production. Jedvert (2014) used $7 \%\left(\mathrm{~m} / \mathrm{m}\right.$ ) of $\mathrm{NaBH}_{4}$ (on a dry wood basis) as the base case when conducting the pretreatment experiments. In these experiments, the $\mathrm{NaBH}_{4}$ concentration was varied from $0.5 \%(\mathrm{~m} / \mathrm{m})$ to $7 \%(\mathrm{~m} / \mathrm{m})$ (Jedvert, 2014) and, although the treatment times were different, only small differences were found between the chemical compositions of the resulting pretreated material following the pretreatment and mild steam explosion. Therefore, the concentration of $\mathrm{NaBH}_{4}$ was varied in order to investigate to what extent potential environmental impacts could be reduced by using less $\mathrm{NaBH}_{4}$. Furthermore, as $\mathrm{NaBH}_{4}$ production required significant amounts of energy, it is also important to assess how changing the energy source for the $\mathrm{NaBH}_{4}$ production process would affect the environmental impacts. In the sensitivity analysis, the environmental impact change of shifting the energy source from the conventional source (modeled by the ecoinvent process 'heat, in chemical industry - RER') to completely from biomass is assessed.

The ecoinvent process model for the fossil-based production of adipic acid assumes that $80 \%$ of the formed $\mathrm{N}_{2} \mathrm{O}$ is removed by abatement technologies (Althaus et al., 2007). However, the catalyzers that are used for this 
removal have been further improved and can reach a removal efficiency of $98 \%$ (Alini et al., 2007). Therefore, a sensitivity analysis is done to assess how such a change in $\mathrm{N}_{2} \mathrm{O}$ removal efficiency may affect the comparison between the different scenarios for bio-based (see Table 1) and the fossil-based adipic acid production.

\section{Results and discussion}

\subsection{Environmental impacts}

The results for the considered impact categories are described in this section. Fig. 2 displays the results for all four scenarios using acid-catalyzed pretreatment, while Fig. 3 displays the results for the scenarios using alkaline pretreatment. In each of the bar charts, the values of the impact for the fossil-based production of adipic acid is mentioned.

\subsubsection{Global warming}

For the base case (BC) scenario, the global warming potential (GWP) results show that adipic acid (AA) production via the bio-based pathway has significant environmental benefits in comparison with the fossilbased pathway. The benefit is more pronounced for the acid-catalyzed pretreatment case, where the GWP is $4.0 \mathrm{~kg}_{\mathrm{CO}_{2} \text {-eq }} \mathrm{kg}_{\mathrm{AA}}^{-1}$, or approx. 6.4 times lower than the GWP of the fossil-based production $\left(25.6 \mathrm{~kg}_{\mathrm{CO}_{2}-\mathrm{eq}} \mathrm{kg}_{\mathrm{AA}}^{-1}\right)$. The GWP result for the alkaline pretreatment case is $7.8 \mathrm{~kg}_{\mathrm{CO}_{2} \text {-eq }} \mathrm{kg}_{\mathrm{AA}}^{-1}$, or approx. 3.3 times lower than the GWP of the fossil-based production (Althaus et al., 2007).

In the acid-catalyzed pretreatment case, the main contributors to GWP are the downstream processing, forest residue pretreatment, and enzyme production (see Fig. 2a). The downstream processing is the most energy-intensive process, as it employs multiple processes for separating adipic acid from the fermentation broth, including crystallization and multi-evaporation. Furthermore, in the BC scenario, a significant amount of fossil fuel is used to produce additional steam for downstream processing, and significantly contributes to the overall GWP. Sc2 has the highest environmental impact because in this scenario lignin is sold as a by-product and therefore more fossil fuel is used to generate process energy. The pretreatment process and enzyme production are the second and third largest contributors to the GWP. The lower GWP for Sc1 is due to the incineration of biomass in addition to lignin by-product incineration in order to generate the process energy needed. Meanwhile, Sc3 has the lowest GWP because in this process only biomass is incinerated to generate process energy, while selling all of the lignin as by-product. Even though Sc3 needs more wood chips, which means more intensive external forestry harvesting activities, the GWP is still lower than that of Sc1, which may be due to the partitioning of environmental impacts between adipic acid and lignin by-product. 
For the alkaline pretreatment case, significant differences in comparison with the acid-catalyzed pretreatment case regarding the main contributing processes to GWP can be observed (see Fig. $3 \mathrm{a}$ ). $\mathrm{NaBH}_{4}$ production and use is the main source of GWP for all scenarios, except for Sc2. The energy in the $\mathrm{NaBH}_{4}$ production is required for the sodium hydride $(\mathrm{NaH})$ synthesis, the subsequent reaction of $\mathrm{NaH}$ with trimethylborate and the extraction of $\mathrm{NaBH}_{4}$ with isopropylamine. In Sc2, the GWP of downstream processing is slightly higher than the GWP of $\mathrm{NaBH}_{4}$ production, since this scenario only uses fossil fuel to generate steam for process energy. For the alkaline pretreatment case, it is important to highlight that the downstream processing in the Sc1 and Sc3 scenarios only has a small contribution to the overall impacts since these scenarios do not use fossil fuel for generating process steam.

\subsubsection{Eutrophication}

The bio-based adipic acid pathway has a much lower eutrophication potential (EP) compared to the EP from the fossil-based pathway (see Figs. $2 b$ and $3 b$ ). The impacts are more evident for the acid-catalyzed pretreatment, where the $\mathrm{EP}$ in the $\mathrm{BC}$ scenario is 6.7 times lower than the $\mathrm{EP}$ of the fossil-based pathway. The overall EP results for scenarios Sc2 and Sc3 are slightly lower than those of the base case and Sc1 scenarios which is mainly due to allocation of the environmental impact to adipic acid and lignin. Furthermore, Sc1 has a lower impact compared to the $\mathrm{BC}$ scenario because of increased biomass utilization for providing energy to the downstream processing. However, increased biomass utilization causes increased emissions from external forestry activities which affect the EP of Sc1 and makes it level off when compared to the EP of the base case. This also occurs for the Sc2 and Sc3 scenarios. Overall, the trend in the EP among the four scenarios (see Figs. $2 \mathrm{~b}$ and $3 \mathrm{~b}$ ) is different compared to those in the other impact categories. This co-variation is further discussed in section 3.3 .

\subsubsection{Acidification}

In the case of acidification potential (AP) for the acid-catalyzed pretreatment case, the overall potential impact of the fossil-based production is lower than those of the BC and Sc2 scenarios (see Fig 2c). This result is different compared to those in other impact categories where typically the bio-based pathway shows significant reductions in environmental impact compared to fossil-based production. This emphasizes the risk of environmental burden shifting (the reduction of specific impacts and an inadvertent increase of other impacts) when developing novel technologies or processes (Laurent and Espinosa, 2015). The trend of the impact over the different scenarios is nevertheless similar to the other impact categories, especially compared to GWP and POCP. 
In all scenarios, $\mathrm{SO}_{2}$ is the highest contributing emission for AP. The main contributing processes for the $\mathrm{BC}$ and Sc2 scenarios in the acid-catalyzed pretreatment case are the downstream processes due to the significant use of fossil fuel to generate process steam. This is mainly due to emissions of $\mathrm{SO}_{2}$ from crude oil processing. In the alkaline pretreatment case (see Fig. 3c), the environmental burden shifting is even more pronounced. The reason is the energy-intensive production of $\mathrm{NaBH}_{4}$ in all scenarios, and downstream processing for the $\mathrm{BC}$ and $\mathrm{Sc} 2$ scenarios. For the $\mathrm{Sc} 1$ and $\mathrm{Sc} 3$ scenarios, the impacts are much lower than those for the BC and Sc2 scenarios because biomass is used as additional energy provider for steam generation. Nevertheless, due to the $\mathrm{NaBH}_{4}$ production the AP for both $\mathrm{Sc} 1$ and $\mathrm{Sc} 3$ scenarios is higher than the AP for the fossil-based production. This result is an example of a critical issue for decision makers: how will they trade off the reduction of GWP against the increase of AP when shifting the adipic acid production from a fossil- to bio-based pathway? The result also gives an indication to decision makers regarding the impact reduction from $\mathrm{NaBH}_{4}$ production, e.g. by establishing a more energy-efficient or cleaner $\mathrm{NaBH}_{4}$ production process or by using less $\mathrm{NaBH}_{4}$ in the alkaline pretreatment process.

\subsubsection{Photochemical ozone creation}

All scenarios, both with the acid-catalyzed and alkaline pretreatments, have a lower photo-chemical ozone creation potential (POCP) compared to the fossil-based pathway (see Figs. 2d and 3d). However, there are less environmental benefits for the alkaline pretreatment cases, because the POCP of the BC and Sc2 scenarios are similar to that of the fossil-based pathway. The POCP in both BC and Sc2 scenarios is mainly caused by the use of fossil energy in the downstream and $\mathrm{NaBH}_{4}$ production processes.

\subsection{Energy use}

The non-renewable and renewable energy use (NREU and REU) results for the scenarios using the acidcatalyzed pretreatment are shown in Fig. 4, while those for the scenarios using the alkaline pretreatment are shown in Fig. 5.

In general, both acid-catalyzed and alkaline pretreatment cases have a lower NREU compared to the fossil-based pathway. The acid-catalyzed pretreatment has a significantly lower NREU (by $62 \%$ ) than the fossil-based pathway in the $\mathrm{BC}$ scenario. In the $\mathrm{BC}$ and $\mathrm{Sc} 2$ scenarios, the most energy-intensive process is the downstream processing, followed by enzyme production and use. Both processes utilize large amounts of fossil fuels to fulfil their energy demands. Since the Sc1 and Sc3 scenarios use external biomass burning as an additional energy source, the NREU decreases sharply by more than $60 \%$ when compared to those of the $\mathrm{BC}$ and $\mathrm{Sc} 2$ scenarios. The enzyme production and use is the most energy-intensive process in both Sc1 
and $\mathrm{Sc} 3$ scenarios. In the alkaline pretreatment, the $\mathrm{NaBH}_{4}$ production is the most energy-intensive process for all scenarios. The NREU of the alkaline BC scenario itself is approx. $15 \%$ lower than the NREU of the fossil-based pathway (in comparison to $62 \%$ for the acid-catalyzed pretreatment case. $\mathrm{NaBH}_{4}$ production contributes $48 \%$ to $77 \%$ to the overall NREU in the four different scenarios. Shifting from fossil fuel to biomass as additional energy source reduces the NREU by approx. $37 \%$ in Sc3, compared to the BC scenario. These results highlight the importance of producing $\mathrm{NaBH}_{4}$ in more efficient and cleaner ways.

The REU is dominated by the forestry harvesting activities. The amount of forest residue needed for the bio-based adipic acid production is the same for all scenarios, and therefore the REU of forestry harvesting is similar for all scenarios. The REU for the Sc2 and Sc3 scenarios is slightly lower due to the allocation of the environmental burdens to adipic acid and lignin pellets. External forestry harvesting plays a major role in the $\mathrm{Sc} 1$ and $\mathrm{Sc} 3$ scenarios due to the increased need of external energy by wood chips incineration. The REU of external forestry harvesting differs approx. $8 \%$ between the acid-catalyzed and alkaline pretreatment scenarios (Figs. 4b and 5b). In comparison to fossil-based adipic acid production, the REU of the BC scenarios for the acid-catalyzed and alkaline pretreatments are 6.6 and 6.9 times higher, respectively. Unlike NREU, the REU for both pretreatment cases is similar. For example, the total REU for the acid-catalyzed and alkaline BC scenarios are $31.8 \mathrm{MJ}$ and 33.5 MJ, respectively. In the other scenarios, the average REU difference between the acid-catalyzed and alkaline pretreatments is only around $4 \%$. This is due to the dominance of REU from forestry harvesting, and due to the fact that $\mathrm{NaBH} 4$ production in the alkaline pretreatment only utilizes a minimum amount of renewable energy sources. This trend is different compared to NREU. The alkaline pretreatment energy demand is 2.2 times higher than the demand of the acid-catalyzed pretreatment in the base case scenario. Unlike in the case of the environmental impact categories and NREU, where the $\mathrm{NaBH}_{4}$ production contributes significantly to the results (from $31 \%$ to $68 \%$ and from $48 \%$ to $77 \%$ of the impact categories and NREU overall values, respectively), the REU of $\mathrm{NaBH}_{4}$ production contributes only $8.6 \%$ to the overall REU of the BC and Sc2 scenarios. In the scenarios with increased external biomass use (Sc1 and Sc3 scenarios) the contribution of $\mathrm{NaBH}_{4}$ production to the REU is only $4.4 \%$ and $3.4 \%$, respectively. These values are much lower than the contribution of $\mathrm{NaBH}_{4}$ production in NREU.

\subsection{Cross-correlation between impact categories and energy use}

The GWP, AP, and POCP show a similar trend over the scenarios (see Figs. 2a, c and d, and 3a, c and d). The NREU results (see Figs. 4a and 5a) strongly correlate with the results of these environmental impact categories, especially with GWP. However, this is not the case for EP as it shows a different trend compared to other impact categories (see Figs. $2 b$ and $3 b$ ). For the case of EP, the REU due to biomass use starts to play a 
dominant role and makes the EP results of the scenarios that use external biomass as additional energy source (Sc1 and Sc3 scenarios, see Table 1) almost the same as those of their fossil fuel counterparts (BC and Sc2 scenarios). The phosphate emissions from the external forestry harvesting processes and biomass incineration for process energy make the EP of the $\mathrm{Sc} 1$ and Sc3 scenarios level with those of the $\mathrm{BC}$ and $\mathrm{Sc} 2$ scenarios.

\subsection{Sensitivity analyses}

\subsubsection{Adipic acid price variation}

The adipic acid (AA) price in the base case scenario was set at $1800 € \mathrm{t}_{\mathrm{AA}}^{-1}$. A price increase from $1800 € \mathrm{t}_{\mathrm{AA}}^{-1}$ to $2500 € \mathrm{t}_{\mathrm{AA}}^{-1}$ will lead to an increase of environmental impact of adipic acid of $4.9 \%$ and $4.1 \%$ for the acidcatalyzed and alkaline pretreatment BC scenario. The environmental impact changes will be more significant if the price goes down from $1800 € \mathrm{t}_{\mathrm{AA}}^{-1}$ to $1100 € \mathrm{t}_{\mathrm{AA}}^{-1}$. The environmental impact reduction compared to the base price for the acid-catalyzed and alkaline pretreatment scenarios will be $9.6 \%$ and $8.1 \%$, respectively.

\subsubsection{Biomass incineration efficiency}

An efficiency improvement of biomass incineration from $75 \%$ to $90 \%$ exhibited the highest environmental impact reduction for the $\mathrm{BC}$ scenario (see Table 3). In general, the GWP is mainly caused by non-renewable energy use (NREU). For the GWP, the reductions are approx. $10 \%$ and $4 \%$ for the acid-catalyzed and alkaline $\mathrm{BC}$ scenarios, respectively. These reductions are mainly due to a lower amount of fossil fuel to fulfil the energy demand in the downstream processing of the $\mathrm{BC}$ scenario. The alkaline $\mathrm{BC}$ scenario has a lower reduction compared to the acid-catalyzed $\mathrm{BC}$ scenario because $\mathrm{NaBH}_{4}$ production is the major contributor to the overall GWP which makes the incineration efficiency improvement become less influential on the overall impact (see Table 3). In the scenarios Sc1 and Sc3 using alkaline pretreatment, the GWP reductions are less than $1 \%$, while the reductions are around $3 \%$ for the scenarios Sc1 and Sc3 using acid-catalyzed pretreatment. The lower GWP reduction for the Sc1 and Sc3 scenarios are because of the higher contributions due to biomass incineration. On average, the GWP reduction in the acid-catalyzed pretreatment scenarios is approx. 3 times higher than for the alkaline pretreatment scenarios.

For the impact categories other than GWP, the reduction in the impacts is also greater for the acid-catalyzed scenarios. The average reductions magnitude for AP, EP and POCP in acid-catalyzed pretreatment case are 2.0, 4.9 and 2.1 times greater than the reductions in the alkaline pretreatment scenarios, respectively (see the Supplementary material). This is due to the high impact of the production of $\mathrm{NaBH}_{4}$. Increasing the biomass incineration efficiency from $75 \%$ to $90 \%$ seems optimistic. However, the results of this sensitivity analysis give decision makers an illustration about the potential environmental benefits and energy use reduction due to 
the increase of biomass combustion efficiency.

\subsection{3. $\mathrm{NaBH}_{4}$ concentration variation}

Reducing the $\mathrm{NaBH}_{4}$ concentration to $5 \%(\mathrm{~m} / \mathrm{m}), 3 \%(\mathrm{~m} / \mathrm{m})$ and $0.5 \%(\mathrm{~m} / \mathrm{m})$ results in a significant reduction of the potential environmental impacts in all scenarios (see Table 4). A significant reduction of NREU is the main reason for this reduction. For the $\mathrm{BC}$ and $\mathrm{Sc} 2$ scenarios, the NREU reductions are between $16 \%$ and $52 \%$, and $14 \%$ and $44 \%$, respectively, while for the $\mathrm{Sc} 1$ and $\mathrm{Sc} 3$ scenarios, the values are almost similar, from $22 \%$ to $71 \%$. Accordingly, the highest reductions in GWP are observed for the Sc1 and Sc3 scenarios. For instance, reducing the $\mathrm{NaBH}_{4}$ concentration to $5 \%(\mathrm{~m} / \mathrm{m})$ and $0.5 \%(\mathrm{~m} / \mathrm{m})$ for Sc1 results in GWP reductions of approx. $19 \%$ and $60 \%$, respectively. For the BC and Sc2 scenarios, the GWP reductions are $13 \%$ and $42 \%$, and $11 \%$ and $35 \%$, respectively. The lower reductions of GWP in the BC and Sc2 scenarios are because of the higher proportion of fossil fuel use for process energy, which makes the environmental benefit due to $\mathrm{NaBH}_{4}$ concentration reduction less influential.

Further experimental research should be conducted in order to optimize pretreatment at lower $\mathrm{NaBH}_{4}$ concentrations. Although the chemical composition of pretreated forest residue will not change significantly at the different concentrations of $\mathrm{NaBH}_{4}$ at the lab scale, other variables should also be taken into consideration, e.g. the reaction time that is needed to pretreat the forest residues with a low concentration of $\mathrm{NaBH}_{4}$.

\subsubsection{Cleaner $\mathrm{NaBH}_{4}$ production process}

In all alkaline pretreatment scenarios, the production and use of $\mathrm{NaBH}_{4}$ contribute significantly to the total environmental impacts. The $\mathrm{NaBH}_{4}$ production was modeled via the reaction of $\mathrm{NaH}$ and trimethylborate pathway, where the required energy was modeled by using ecoinvent process 'heat, in chemical industry RER'. Changing this energy source to biomass only resulted in a significant reduction of the environmental impact. This is due to the reduction of NREU by $25 \%$ to $41 \%$. For GWP, the highest impact reduction was in the Sc1 and Sc3 scenarios, for which a reduction of approx. 32\% in GWP was observed. The GWP reduction for the BC and Sc2 scenarios were $22 \%$ and $19 \%$, respectively (see Table 5). The impact reductions in the $\mathrm{Sc} 1$ and Sc3 scenarios are higher because the relative contribution from $\mathrm{NaBH}_{4}$ production and use to the overall impacts was higher than in the case of the BC and Sc2 scenarios. It should be noted that replacing the conventional energy source with biomass only will increase biomass extraction, in this case round wood, in order to provide the amount of energy needed for $\mathrm{NaBH}_{4}$ production. Furthermore, this sensitivity analysis was only performed for the base case concentration of $\mathrm{NaBH} 4$, which is $7 \%(\mathrm{~m} / \mathrm{m})$.

The best environmental performance of the alkaline scenarios would be obtained if the energy in the 
$\mathrm{NaBH}_{4}$ production process is provided completely by biomass incineration and the pretreatment is performed at $0.5 \%(\mathrm{~m} / \mathrm{m}) \mathrm{NaBH}_{4}$ concentration.

\subsubsection{Increased $\mathrm{N}_{2} \mathrm{O}$ removal efficiency}

Increasing the removal efficiency of $\mathrm{N}_{2} \mathrm{O}$ from $80 \%$ to $98 \%$ results in a reduction of its emission from $6.02 \times 10^{-2} \mathrm{~kg}_{\mathrm{N}_{2} \mathrm{O}} \mathrm{kg}_{\mathrm{AA}}^{-1}$ to $6.02 \times 10^{-3} \mathrm{~kg}_{\mathrm{N}_{2} \mathrm{O}} \mathrm{kg}_{\mathrm{AA}}^{-1}$ in the ecoinvent process model for fossil-based adipic acid production. Consequently, the GWP and EP of the fossil-based production decreased significantly from $25.6 \mathrm{~kg}_{\mathrm{CO}_{2}-\mathrm{eq}} \mathrm{kg}_{\mathrm{AA}}^{-1}$ to $9.4 \mathrm{~kg}_{\mathrm{CO}_{2} \text {-eq }} \mathrm{kg}_{\mathrm{AA}}^{-1}$ (a reduction of $63 \%$ ), and from $2.90 \times 10^{-2} \mathrm{~kg}_{\mathrm{PO}_{4}{ }^{3-}-\mathrm{eq}} \mathrm{kg}_{\mathrm{AA}}^{-1}$ to $1.44 \times 10^{-2} \mathrm{~kg}_{\mathrm{PO}_{4}{ }^{3-}{ }_{-} \mathrm{eq}} \mathrm{kg}_{\mathrm{AA}}^{-1}$ (a reduction of $50 \%$ ), respectively. The AP and POCP were not affected by the reduction of $\mathrm{N}_{2} \mathrm{O}$ emissions.

The fossil-based production of adipic acid continues to have a worse performance for both GWP and EP when compared to the acid-catalyzed scenarios for its bio-based production (see Fig. 2). The difference in GWP between the fossil-based and bio-based production is at least $48 \%$ (scenario Sc2, see Fig. 2a), and at least $70 \%$ for EP (scenarios BC and Sc1, see Fig. 2b). However, for the alkaline scenarios, the EP of the base case and Sc1 scenarios are similar to the EP of the fossil-based production (see Fig. 3b). Nevertheless, the GWP of the bio-based production scenarios remains lower although the difference between the GWP of the base case and $\mathrm{Sc} 2$ scenarios is reduced to $1.6 \mathrm{~kg}_{\mathrm{CO}_{2}-\mathrm{eq}} \mathrm{kg}_{\mathrm{AA}}^{-1}$ and $1.3 \mathrm{~kg}_{\mathrm{CO}_{2} \text {-eq }} \mathrm{kg}_{\mathrm{AA}}^{-1}$, respectively (see Fig. 3a). It should be noted however that when the $\mathrm{GaBi}$ process data set for fossil-based adipic acid production (Thinkstep, 2017) is used, the GWP further drops to between $6.3 \mathrm{~kg}_{\mathrm{CO}_{2}-\mathrm{eq}} \mathrm{kg}_{\mathrm{AA}}^{-1}$ and $7.2 \mathrm{~kg}_{\mathrm{CO}_{2}-\mathrm{eq}} \mathrm{kg}_{\mathrm{AA}}^{-1}$. Fossil-based production then outperforms the alkaline base case and Sc2 scenarios. Despite a better environmental performance of the fossil-based production of adipic acid due to reduced $\mathrm{N}_{2} \mathrm{O}$ emissions, it does not become competitive (from an environmental point-of-view) with any of the acid-catalyzed bio-based production scenarios. However, in the case of the alkaline bio-based production scenarios, the EP of the fossil-based production is similar to the EP of these scenarios, and thus needs to be considered carefully (next to AP, see section 3.1.3) in order to guarantee a better environmental performance of the bio-based production of adipic acid.

\section{Conclusion}

In this study, a prospective life cycle assessment (LCA) of adipic acid production from forest residues at an early development stage was conducted. Two different pretreatment methods, acid-catalyzed and alkaline, were employed and scenarios and sensitivity analyses were conducted. The potential environmental impacts of this alternative bio-based pathway were compared to those of fossil-based adipic acid. For most of the impact categories (GWP, EP and POCP), the bio-adipic acid production from forest residues shows significant 
environmental benefits compared to the fossil-based pathway. This benefit will be higher when more renewable resources such as biomass are used to fulfil the process energy demands.

Overall, the sensitivity analyses emphasize the potential environmental benefit of using biomass as a source for process energy, either in the bio-adipic acid or $\mathrm{NaBH}_{4}$ production. Efficiency improvement of biomass incineration will also reduce the potential environmental impacts. Furthermore, as alkaline pretreatment has higher potential environmental impacts than the acid pretreatment, it is important to reduce the amount of $\mathrm{NaBH}_{4}$ used in the pretreatment. Further research will be needed in order to investigate the feasibility of using a lower amount of $\mathrm{NaBH}_{4}$ at a larger scale.

\section{Supplementary material}

Supplementary data are available as an electronic annex.

\section{Acknowledgements}

This study was funded by The Swedish Research Council for Environment, Agricultural Sciences and Spatial Planning (FORMAS; Stockholm, Sweden, BioBUF project, grant number 213-2013-78). The authors would also like to acknowledge Achille-B. Laurent at Maastricht University's Department of Biobased Material for providing data about the fossil-based adipic acid production process.

\section{References}

Alini, S., Basile, F., Blasioli, S., Rinaldi, C., Vaccari, A., 2007. Development of new catalysts for $\mathrm{N}_{2} \mathrm{O}-$ decomposition from adipic acid plant. Appl Catal B 70, 323-329.

Althaus, H.-J., Chudacoff, M., Hischier, R., Jungbluth, N., Osses, M., Primas, A., 2007. Life cycle inventories of chemicals. Tech. Rep. ecoinvent report No. 8, EMPA Dübendorf.

Boswell, C., Meehan, J., 2011. European adipic acid prices stumble after long run-up. ICIS Chemical Business 280, 18-19.

Burgard, A. P., Pharkya, P., Osterhout, R. E., 2013. Microorganisms for the production of adipic acid and other compounds. US patent no. 8592189 B2.

Ciroth, A., 2007. ICT for Environment in Life Cycle Applications openLCA - A new open source software for Life Cycle Assessment. Int J Life Cycle Assess 12, 209-210. 
Danish Energy Agency, 2011. Energy strategy 2050 - from coal, oil and gas to green energy. Tech. rep., Danish Energy Agency.

Draths, K. M., Frost, J. W., 1994. Environmentally compatible synthesis of adipic acid from D-glucose. J Am Chem Soc 116, 399-400.

Energimyndigheten, 2014. Energy in sweden 2013. Tech. rep., Energimyndigheten.

Frischknecht, R., Jungbluth, N., Althaus, H.-J., Bauer, C., Doka, G., Dones, R., Hischier, R., Hellweg, S., Humbert, S., Köllner, T., Loerincik, Y., Margni, M., Nemecek, T., 2007. Implementation of life cycle impact assessment methods. Tech. Rep. ecoinvent report No. 3, Swiss Centre for Life Cycle Inventories.

Guinée, J., Gorrée, M., Heijungs, R., Huppes, G., Kleijn, R., Koning, A. d., Oers, L. v., Wegener Sleeswijk, A., Suh, S., Udo de Haes, H., Bruijn, H. d., Duin, R. v., Huijbregts, M., 2002. Handbook on life cycle assessment. Operational guide to the ISO standards. Kluwer Academic Publishers, Dordrecht.

Han, J., 2016. A bio-based 'green' process for catalytic adipic acid production from lignocellulosic biomass using cellulose and hemicellulose derived $\gamma$-valerolactone. Energy Convers Manage 129, 75-80.

Hoelderich, W. F., 2000. Environmentally benign manufacturing of fine and intermediate chemicals. Catal Today 62, 115-130.

Janssen, M., Xiros, C., Tillman, A.-M., 2016. Life cycle impacts of ethanol production from spruce wood chips under high gravity conditions. Biotechnol Biofuels 9, 53.

Jedvert, K., 2014. Mild steam explosion of Norway spruce. Ph.D. thesis, Chalmers University of Technology. URL http://publications.lib.chalmers.se/records/fulltext/197017/197017.pdf

Jedvert, K., Saltberg, A., Lindström, M. E., Theliander, H., 2012. Mild steam explosion and chemical pretreatment of Norway spruce. Bioresources 7, 2051-2074.

Karlsson, H., Börjesson, P., Hansson, P.-A., Ahlgren, S., 2014. Ethanol production in biorefineries using lignocellulosic feedstock - GHG performance, energy balance and implications of life cycle calculation methodology. J Clean Prod 83, 420-427.

Laurent, A., Espinosa, N., 2015. Environmental impacts of electricity generation at global, regional and national scales in 1980-2011: what can we learn for future energy planning? Energy Environ Sci 8, 689-701. 
Li, L., Xu, J., Hu, J., Han, J., 2014. Reducing Nitrous Oxide Emissions to Mitigate Climate Change and Protect the Ozone Layer. Environ Sci Technol 48, 5290-5297.

Liptow, C., Tillman, A.-M., Janssen, M., Wallberg, O., Taylor, G., 2013. Ethylene based on woody biomass: what are environmental key issues of a possible future Swedish production on industrial scale. Int J Life Cycle Assess 18, 1071-1081.

Myhre, G., Shindell, D., Bréon, F.-M., Collins, W., Fuglestvedt, J., Huang, J., Koch, D., Lamarque, J.-F., Lee, D., Mendoza, B., Nakajima, T., Robock, A., Stephens, G., Takemura, T., Zhang, H., 2013. Anthropogenic and Natural Radiative Forcing. Cambridge University Press, Cambridge, United Kingdom and New York, NY, USA, Ch. 8, pp. 659-740.

NREL, 2012. U.S. life cycle inventory database. Accessed April 2016.

URL https://www.lcacommons.gov/nrel/search

Ortiz, C. A., Lundblad, M., Lundström, A., Stendahl, J., 2014. The effect of increased extraction of forest harvest residues on soil organic carbon accumulation in sweden. Biomass Bioenerg 70, 230-238.

Palmqvist, B., Liden, G., 2012. Torque measurements reveal large process differences between materials during high solid enzymatic hydrolysis of pretreated lignocellulose. Biotechnol Biofuels 5, 57.

Qin, C., 2009. Lignin as alternative renewable fuel.

URL http://www.altenergymag.com/emagazine/2009/06/lignin-as-alternative-renewable-fuel/1384

Sandén, B., Pettersson, K., 2014. System Perspectives on Biorefineries. Chalmers Energy Initiative.

Schweigler, T., 2016. Process development of integrated biorefinery concepts at different technology readiness level. Master's thesis, ETH Zürich.

Shimizu, A., Tanaka, K., Fujimori, M., 2000. Abatement technologies for $\mathrm{N}_{2} \mathrm{O}$ emissions in the adipic acid industry. Chemosphere Global Change Sci 2, 425-434.

Svensson, E., Janssen, M., Pettersson, K., Ekman, A., 2015. Economic and environmental analysis of an emerging biorefinery concept as a guide for early technology development. In: $10^{\text {th }}$ Conference on Sustainable Development of Energy, Water and Environment Systems. pp. 1-6.

Thinkstep, 2017. Process data set: Adipic acid; via cyclohexane; production mix, at plant. Online, accessed February 2017. 
van Duuren, J., Brehmer, B., Mars, A., Eggink, G., dos Santos, V. M., Sanders, J., 2011. A limited LCA of bio-adipic acid: Manufacturing the nylon-6,6 precursor adipic acid using the benzoic acid degradation pathway from different feedstocks. Biotechnol Bioeng 108, 1298-1306.

Wang, Q., Gürsel, I. V., Shang, M., Hessel, V., 2013. Life cycle assessment for the direct synthesis of adipic acid in microreactors and benchmarking to the commercial process. Chem Eng J 234, 300-311.

Wu, Y., Kelly, M. T., Ortega, J. V., 2004. Review of chemical processes for the synthesis of sodium borohydride. Tech. rep., Millennium Cell Inc.

URL https://www.eecbg.energy.gov/hydrogenandfuelcells/pdfs/review_chemical_processes.pdf 


\section{Table captions}

\section{Table 1}

Description of the analyzed scenarios

\section{Table 2}

The price of the products of the process

\section{Table 3}

The reduction of GWP and NREU for each scenario (acid-catalyzed and alkaline pretreatment) when biomass incineration efficiency is increased from $75 \%$ to $90 \%$

\section{Table 4}

The reduction of GWP and NREU due to the reduction of $\mathrm{NaBH}_{4}$ concentration

\section{Table 5}

The reduction of GWP and NREU when process energy for the $\mathrm{NaBH}_{4}$ production is changed from the ecoinvent process 'heat, in chemical industry - RER' to biomass only 


\section{Figure captions}

Fig. 1. Process diagram of bio-based adipic acid production. Note: *applied to $\mathrm{BC}$ and $\mathrm{Sc} 1$ scenarios where lignin by-product is incinerated to generate process energy; **applied to $\mathrm{Sc} 2$ and $\mathrm{Sc} 3$ scenarios where lignin by-product is sold (see section 2.2.3 for the scenario descriptions).

Fig. 2. Environmental impacts of the production of bio-based adipic acid using acid-catalyzed ptreatment for the defined scenarios: a. global warming potential (GWP), b. eutrophication potential (EP), c. acidification potential (AP), and d. photochemical ozone creation potential (POCP). The impact of fossil-based adipic acid production is mentioned in each graph.

Fig. 3. Environmental impacts of the production of bio-based adipic acid using alkaline ptreatment for the defined scenarios: a. global warming potential (GWP), b. eutrophication potential (EP), c. acidification potential (AP), and d. photochemical ozone creation potential (POCP). The impact of fossil-based adipic acid production is mentioned in each graph.

Fig. 4. Energy use in the production of bio-based adipic acid using acid-catalyzed ptreatment for the defined scenarios: a. non-renewable energy use (NREU), and b. renewable energy use (NREU). The energy use of fossil-based adipic acid production is mentioned in each graph.

Fig. 5. Energy use in the production of bio-based adipic acid using alkaline ptreatment for the defined scenarios: a. non-renewable energy use (NREU), and b. renewable energy use (REU). The energy use of fossil-based adipic acid production is mentioned in each graph. 


\section{Tables}

Table 1

\begin{tabular}{ccl}
\hline Scenario name & Lignin by-product & Additional energy source \\
\hline BC (base case) & incinerated & biogas, lignin, fossil fuel \\
Sc1 & incinerated & biogas, lignin, external biomass \\
Sc2 & sold & biogas, fossil fuel \\
Sc3 & sold & biogas, external biomass \\
\hline
\end{tabular}


Table 2

\begin{tabular}{lc}
\hline Products & Price $\left[€ \mathrm{t}^{-1}\right]$ \\
\hline Adipic acid & $1800^{1}$ \\
Lignin & $300^{2}$ \\
\hline 1 & Boswell and Meehan (2011) \\
2 & Assumed to be sold as an al- \\
ternative renewable fuel (Qin, \\
2009).
\end{tabular}


Table 3

\begin{tabular}{lcccc}
\hline Scenario & \multicolumn{2}{c}{ Acid-catalyzed pretreatment } & \multicolumn{2}{c}{ Alkaline pretreatment } \\
& $\Delta$ GWP [\%] & $\Delta$ NREU [\%] & $\Delta$ GWP [\%] & $\Delta$ NREU [\%] \\
\hline BC & -10.0 & -9.9 & -4.1 & -3.6 \\
Sc1 & -2.8 & -2.8 & -0.4 & -0.2 \\
Sc3 & -2.9 & -3.7 & -0.6 & -0.4 \\
\hline
\end{tabular}


Table 4

\begin{tabular}{lccc}
\hline Scenario & $\begin{array}{c}\mathrm{NaBH}_{4} \text { concentration } \\
{[\%(\mathrm{~m} / \mathrm{m})]}\end{array}$ & \multicolumn{2}{c}{ Changes [\%] } \\
& 5 & -13 & -16 \\
$\mathrm{BC}$ & 3 & -26 & -32 \\
& 0.5 & -42 & -52 \\
\hline \multirow{3}{*}{$\mathrm{Sc} 1$} & 5 & -19 & -22 \\
& 3 & -37 & -44 \\
& 0.5 & -60 & -72 \\
\hline & 5 & -11 & -14 \\
$\mathrm{Sc} 2$ & 3 & -22 & -27 \\
& 0.5 & -35 & -44 \\
\hline \multirow{3}{*}{$\mathrm{Sc} 3$} & 5 & -18 & -22 \\
& 3 & -37 & -44 \\
& 0.5 & -60 & -71 \\
\hline
\end{tabular}


Table 5

\begin{tabular}{lcc}
\hline Scenario & \multicolumn{2}{c}{ Changes [\%] } \\
& GWP & NREU \\
\hline BC & -22 & -30 \\
Sc1 & -32 & -41 \\
Sc2 & -19 & -25 \\
Sc3 & -32 & -41 \\
\hline
\end{tabular}




\section{Figures}

Figure 1

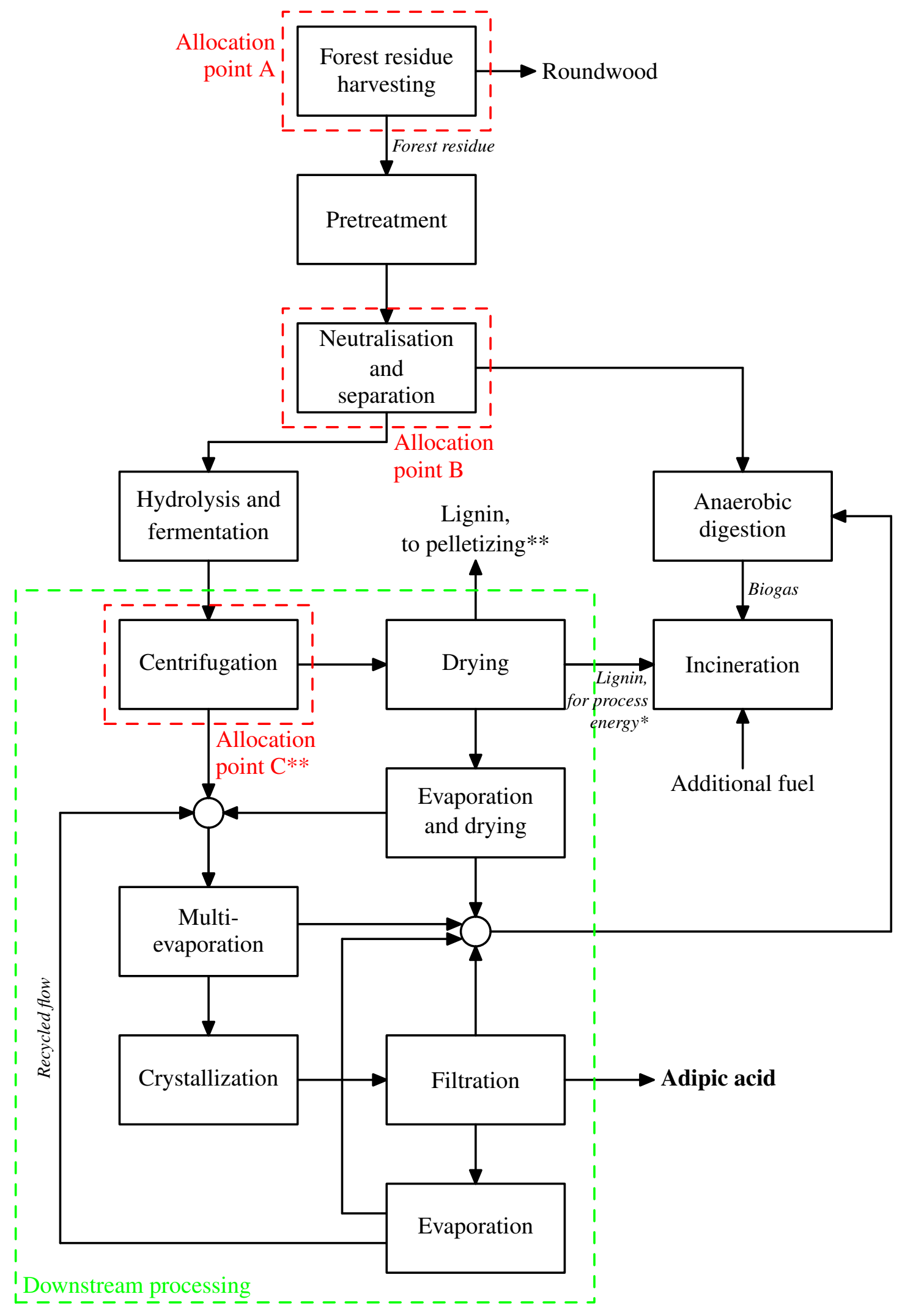


Figure 2

a.
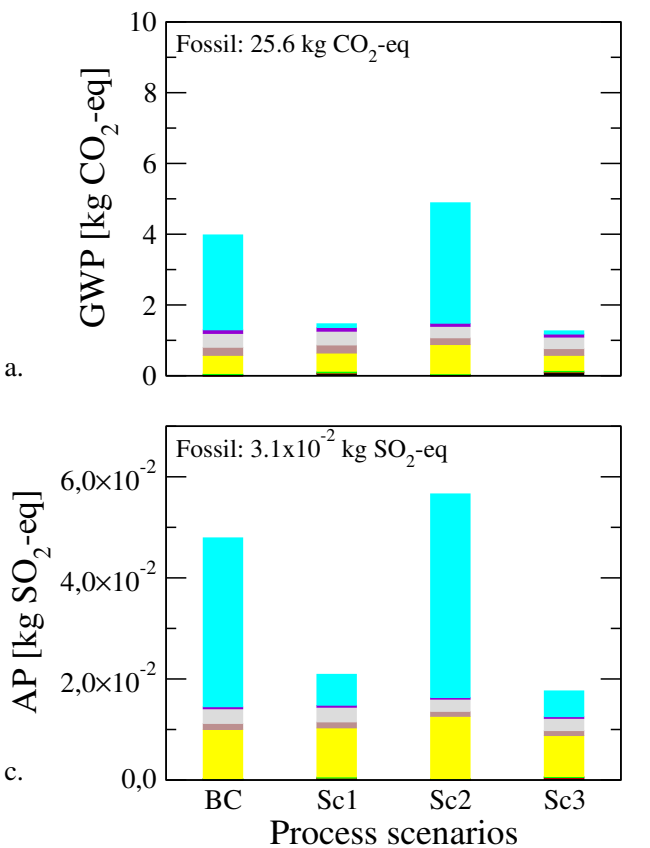

b.
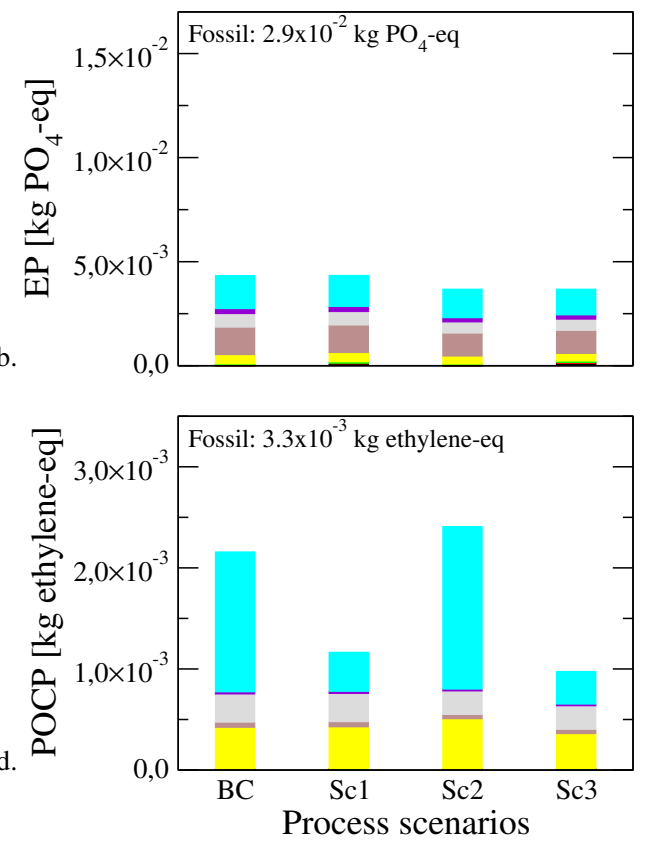

External forestry

Sawmill plant

Forest harvesting

Forest residue pretreatment

Forest residue neutralization

Enzyme production and use

Hydrolysis \& fermentation

Downstream processing

Base case - lignin incinerated, fossil fuel for additional energy needs

Scenario 1 - lignin incinerated, biomass for additional energy needs

Scenario 2 - lignin sold, fossil fuel for additional energy needs

Scenario 3 - lignin sold, biomass

for additional energy needs 
Figure 3

a.
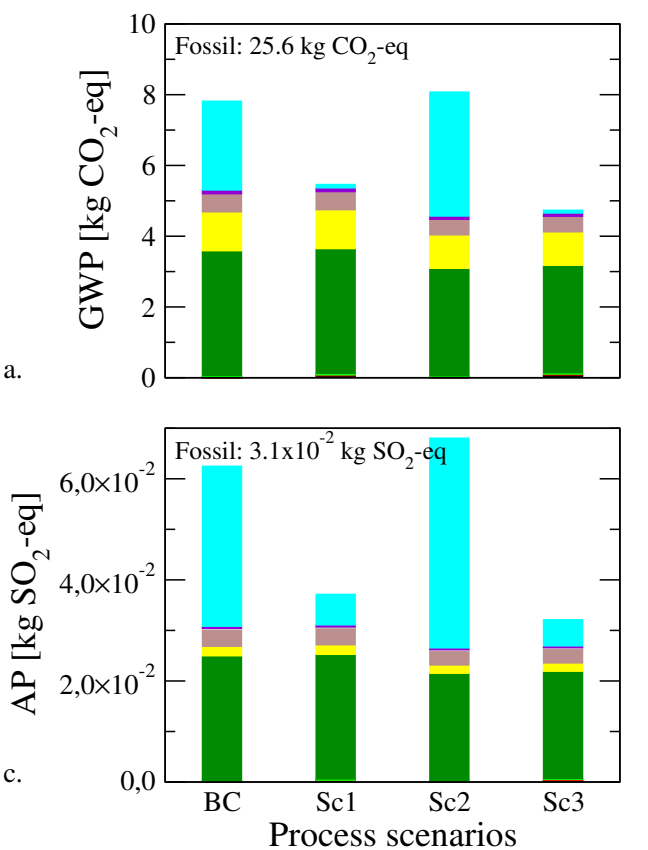
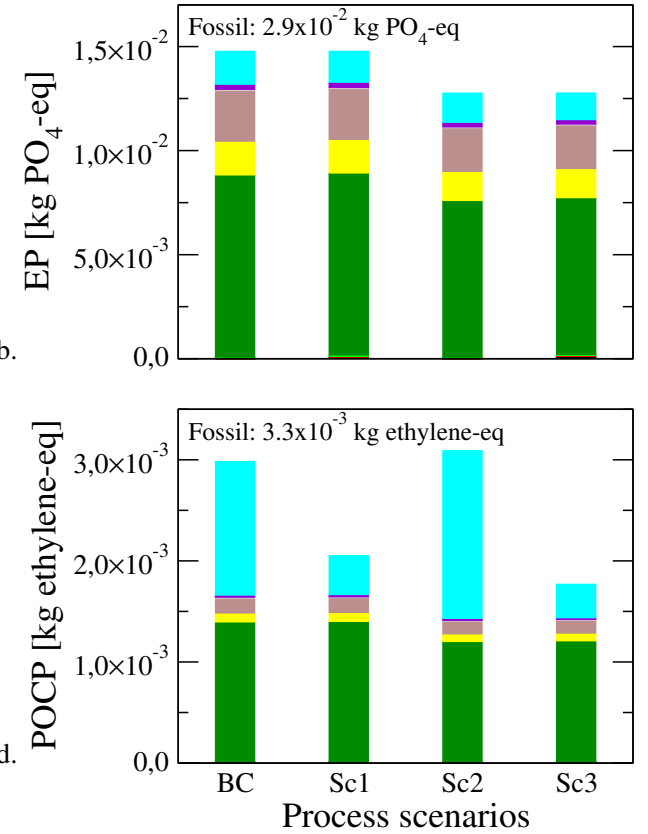

External forestry

Sawmill plant

Forest harvesting

$\mathrm{NaBH}_{4}$ production and use

Forest residue pretreatment

Forest residue neutralization

Hydrolysis \& fermentation

Downstream processing

Base case - lignin incinerated, fossil fuel for additional energy needs

Scenario 1 - lignin incinerated, biomass for additional energy needs

Scenario 2 - lignin sold, fossil fuel for additional energy needs

Scenario 3 - lignin sold, biomass

for additional energy needs 


\section{Figure 4}
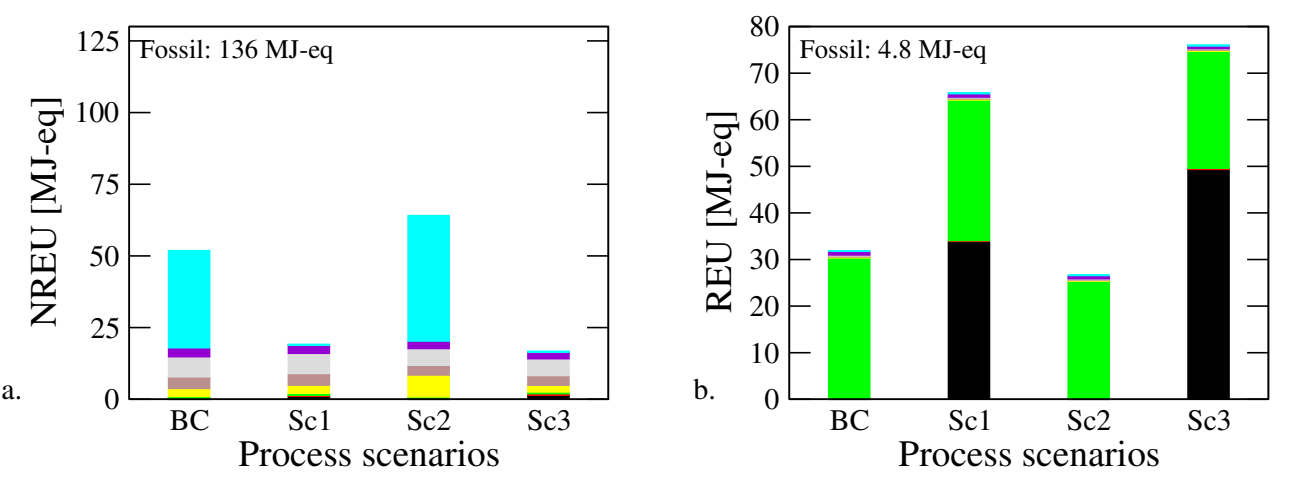
External forestry
Sawmill plant
Forest harvesting
Forest residue pretreatment
Forest residue neutralization
Enzyme production and use
Hydrolysis \& fermentation
Downstream processing

Base case - lignin incinerated, fossil fuel for additional energy needs

Scenario 1 - lignin incinerated, biomass for additional energy needs

Scenario 2 - lignin sold, fossil fuel for additional energy needs

Scenario 3 - lignin sold, biomass for additional energy needs 


\section{Figure 5}
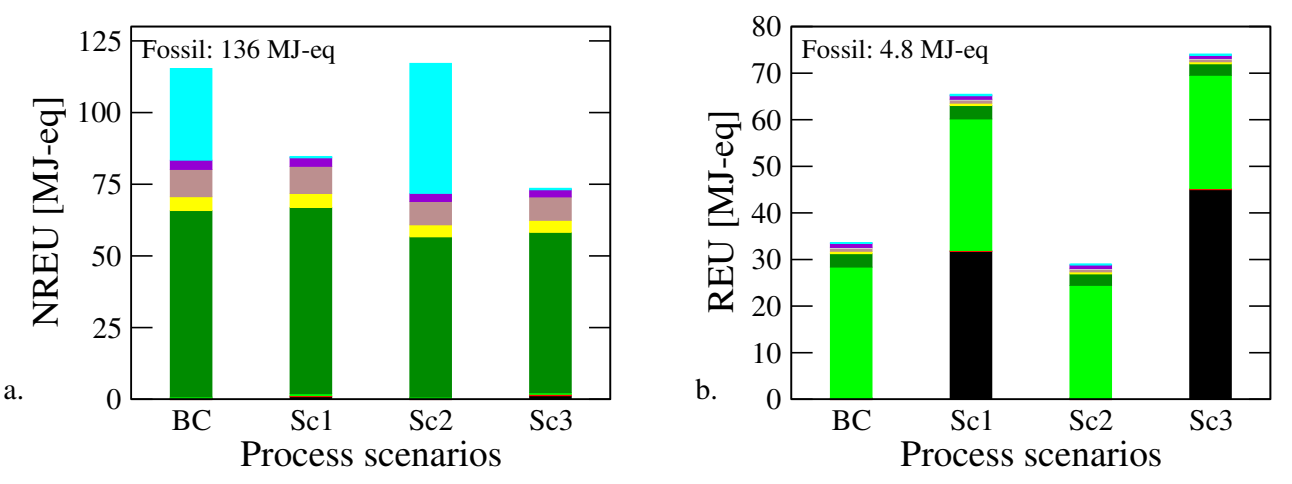

\begin{tabular}{|l|}
\hline External forestry \\
Sawmill plant \\
Forest harvesting \\
$\mathrm{NaBH}_{4}$ production and use \\
Forest residue pretreatment \\
Forest residue neutralization \\
Hydrolysis \& fermentation \\
Downstream processing \\
\hline
\end{tabular}

Base case - lignin incinerated, fossil fuel for additional energy needs

Scenario 1 - lignin incinerated, biomass for additional energy needs

Scenario 2 - lignin sold, fossil fuel for additional energy needs

Scenario 3 - lignin sold, biomass for additional energy needs 